\title{
The United Kingdom's first NHS Endobarrier service for advanced diabesity: 1-year outcomes for all 62 treated patients
}

\author{
ROBERT EJ RYDER, SUSAN P IRWIN, WYN BURBRIDGE, HARDEEP GANDHI, TAHIRA BASHIR, \\ RACHAEL A ALLDEN, MORDEL WILSON, MELANIE WYRES, MELISSA CULL, MAHI YADAGIRI, \\ JOHN P BLEASDALE, EDWARD N FOGDEN, MARK R ANDERSON, PIYA SEN GUPTA
}

\begin{abstract}
Aims: EndoBarrier is a $60 \mathrm{~cm}$ proximal intestinal liner, endoscopically implanted for up to 1 year, designed to mimic the bypass aspect of Roux-en-Y gastric bypass surgery. We aimed to assess its safety and efficacy in patients with advanced diabesity.

Methods: Since October 2014 we have implanted 62 EndoBarriers in our NHS service. By November 2018 all were explanted. Outcomes were monitored in a registry.

Results: In 61 of the 62 patients $(98.4 \%$ ) (age $51.4 \pm 7.2$ years, $54.1 \%$ male, $57.4 \%$ Europid, diabetes duration 12.0 (8.0-19.5) years, $57.4 \%$ insulin-treated, BMI $41.9 \pm 7.4$ $\mathrm{kg} / \mathrm{m}^{2}$ ) with implant and explant data, mean \pm SD HbA $1 \mathrm{c}$ fell by $23.7 \pm 21.4 \mathrm{mmol} / \mathrm{mol}$ from $80.2 \pm 22.5$ to $56.5 \pm 11.5$ $\mathrm{mmol} / \mathrm{mol}(p<0.001)$, weight fell by $15.9 \pm 8.5 \mathrm{~kg}$ from $122.6 \pm 27.9$ to $106.7 \pm 28.9 \mathrm{~kg}(p<0.001)$, systolic blood pressure from $138.5 \pm 15.0$ to $125.8 \pm 14.6 \mathrm{mmHg}(p<0.001)$, cholesterol from $4.7 \pm 1.4$ to $3.9 \pm 0.9 \mathrm{mmol} / \mathrm{L}(p<0.001)$ and alanine aminotransferase (a marker for non-alcoholic fatty liver disease) from $33.2 \pm 19.8$ to $19.5 \pm 11.4 \mathrm{U} / \mathrm{L}(\mathrm{p}<0.001)$. In the 35 insulin-treated patients, median (IQR) insulin dose reduced from $100(54-140)$ to $40(0-70)$ units $(p<0.001)$, with $10 / 35(28.6 \%)$ discontinuing insulin. There were significant falls (UKPDS Risk Engine v2) in the risk of coronary heart disease (CHD) and stroke, suggesting that EndoBarrier treatment in 100 such patients could prevent 8 events of CHD or stroke and save 6 lives over the 10 years. Ten of the 62 patients ( $16 \%$ ) required early removal (4 for gastrointestinal haemorrhage, 2 for liver abscess, 1 for another intra-abdominal abscess and 3 for gastrointestinal symptoms). All made a full recovery following
\end{abstract}

Sandwell \& West Birmingham NHS Trust, City Hospital, Birmingham, UK

Address for correspondence: Dr Bob Ryder

Sandwell \& West Birmingham NHS Trust, City Hospital, Dudley Road,

Birmingham B18 7QH, UK

Tel: 01215074591

E-mail: bob.ryder@nhs.net

https://doi.org/10.15277/bjd.2019.226 device removal and most derived benefit despite early removal.

Conclusion: EndoBarrier was highly effective in this setting in patients with advanced diabetes and obesity. Given the high cardiovascular and microvascular risk of these patients, benefits might outweigh risks. As an endoscopic procedure it is relatively simple and non-invasive. Early removal rates require monitoring and there needs to be increased focus on preventing complications but, on balance, EndoBarrier deserves further investigation as a potential treatment for wider use.

Br J Diabetes 2019;19:110-117

Key words: EndoBarrier, duodenal-jejunal bypass liner, DJBL, obesity, type 2 diabetes, diabesity, bariatric surgery

\section{Introduction}

\section{Background and rationale}

EndoBarrier ${ }^{\circledast}$ (GI Dynamics, Boston, USA), also known as the duodenal-jejunal bypass liner, is a $60 \mathrm{~cm}$ long impermeable fluoropolymer sleeve which is implanted by endoscopy into the first part of the small intestine where it remains for up to 1 year (Figure 1). It is held in place by a nitinol anchor, such that food passes through it without coming into contact with the small intestine, thereby interfering with the normal digestive processes that occur in this region. Pancreatic and bile secretions mix with the undigested nutrients at the distal end of the EndoBarrier. Thus, it mimics the bypass aspect of Roux-en-Y gastric bypass surgery. ${ }^{1-6}$ The endoscopic insertion and removal of EndoBarrier are day case procedures, performed in less than an hour, usually under general anaesthesia. This form of reversible bariatric procedure has been shown to reduce weight and improve glycaemic control in patients with diabetes and obesity. ${ }^{2-6}$

REVISE-Diabesity (Randomisation to EndoBarrier alone Versus with Incretin analogue in SustainEd Diabesity), an Association of British Clinical Diabetologists (ABCD) UK-funded, multicentre, randomised controlled trial (ISRCTN00151053) led by our institution supports these observations. Additionally, preliminary data on the first year of treatment with the EndoBarrier device combined with liraglutide therapy showed benefit on $\mathrm{HbA}_{1 \mathrm{c}}$ and weight/body 
Figure 1. The Endobarrier device $(A)$ and a diagram of the device in situ (B)
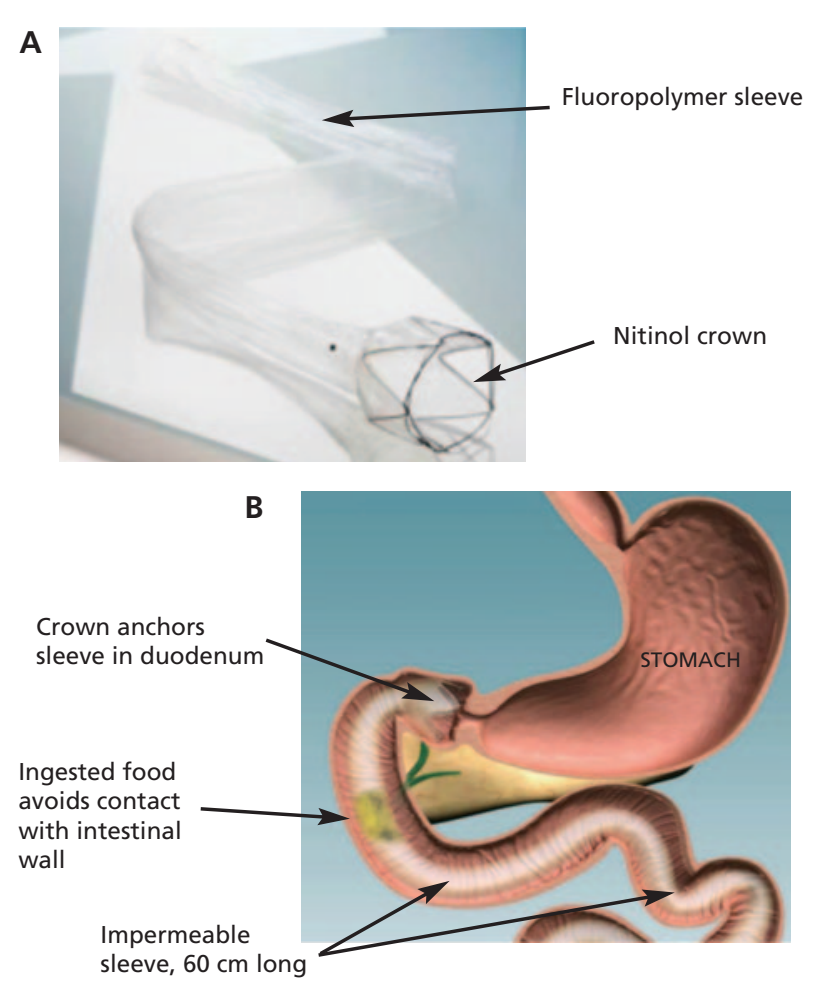

Adapted from http://www. diabetologistsabcd.org.uk/Research/What_Endobarrier.htm.

mass index (BMI) and liver fat. ${ }^{7-9}$ Despite the growing evidence of benefits, EndoBarrier treatment has not been tried as part of a routine diabetes NHS service.

There is currently a worldwide pandemic of type 2 diabetes. The International Diabetes Federation (IDF) describes this as 'a global emergency'. ${ }^{10}$ Type 2 diabetes is driven by obesity. ${ }^{11}$ Management comprises a lifestyle programme focused on weight loss achieved through education with changes to diet and increased exercise. If target levels for glycaemic control are not achieved, pharmacological options include metformin, sulfonylureas, pioglitazone, metiglinides, alpha glucosidase inhibitors, DPP4 inhibitors, SGLT2 inhibitors and GLP-1 receptor agonists; beyond these medications, insulin can be initiated. ${ }^{12,13}$ In view of insulin resistance, which is a feature of type 2 diabetes, high doses may be required. ${ }^{14}$ The use of insulin, however, is associated with increase in weight, ${ }^{15,16}$ which is counterintuitive in patients who are already obese. Bariatric/metabolic surgery is a proven alternative option in this situation. ${ }^{17-19} \mathrm{~A}$ less established and less invasive option for achieving temporary proximal intestinal bypass is with the use of the EndoBarrier device. The advantages of this approach include the lack of permanence of the intervention rather than permanent changes to the anatomy, with lesser invasiveness and no open wounds following surgery. In view of these advantages, many patients express a preference for this procedure.
We aimed to evaluate whether the experience acquired through the REVISE-Diabesity study could translate into establishment of a safe and effective NHS EndoBarrier service for patients with sub-optimally controlled type 2 diabetes and obesity. In order to establish the service we aimed to:

- design a comprehensive 2-year patient pathway

- consult with relevant teams and patients

- obtain management support

- agree funding system with local service commissioners

- prime patients to maintain improvements after device removal by suggesting institution of behaviour changes during EndoBarrier treatment

- establish a secure online registry ${ }^{20}$ to monitor outcomes prospectively

Once established, we aimed to audit the impact of EndoBarrier therapy on weight, $\mathrm{BMI}, \mathrm{HbA}_{1 \mathrm{c}}$, systolic blood pressure, cholesterol, HDL cholesterol, cardiovascular risk as assessed by the UKPDS Risk Engine v2, ${ }^{21}$ alanine aminotransferase as a marker of liver fat, ${ }^{9}$ daily insulin dose and insulin discontinuation rate. We also aimed to audit the rate of serious adverse events and early removal due to side effects.

\section{Methods}

\section{Study design and setting}

We designed a comprehensive 2-year pathway, as outlined in Figure 2. Patients were seen at the Diabetes Centre at City Hospital in Birmingham, UK, in NHS clinics specifically set up for the purpose. The gastroenterologists responsible for EndoBarrier procedures saw the patients in a different clinic in the same setting. The insertion and removal procedures were carried out in an interventional radiology or fluoroscopic screening room by the two gastroenterologists with the support of an anaesthetist and operating department practitioner, endoscopy nursing staff trained in EndoBarrier insertion and removal techniques, and a radiographer. The first EndoBarrier implantation in the NHS service was in October 2014 and the last one in November 2017, with the last EndoBarrier being removed in November 2018.

\section{Participants}

All patients had type 2 diabetes, were aged between 28 and 70 years, BMI $>30 \mathrm{~kg} / \mathrm{m}^{2}$ and had tried diet, lifestyle and medications including GLP-1 receptor agonists and, once available, SGLT2 inhibitors if within licence. Thus, the only options left for them were to start insulin, increase insulin further if already on insulin, or have bariatric/metabolic surgery or alternative procedures not yet available on the $\mathrm{NHS}$. $\mathrm{HbA}_{1 \mathrm{c}}>58 \mathrm{mmol} / \mathrm{mol}(7.5 \%)$ was generally required. Lower $\mathrm{HbA}_{1 c}$ was acceptable only if patients were already established on insulin and the diabetologist considered that the patient's insulin treatment to maintain the lower $\mathrm{HbA}_{1 \mathrm{c}}$ was contributing significantly to the obesity. Patients were considered for EndoBarrier based on $\mathrm{HbA}_{1 \mathrm{c}}$ assessed at the screening visit. If at that visit they fulfilled the criteria and they wished to proceed, they were then assessed by the gastroenterologists who would insert the EndoBarrier and, if they were accepted by them, they went onto a waiting list. 
Figure 2. Comprehensive 2-year patient pathway for NHS EndoBarrier service

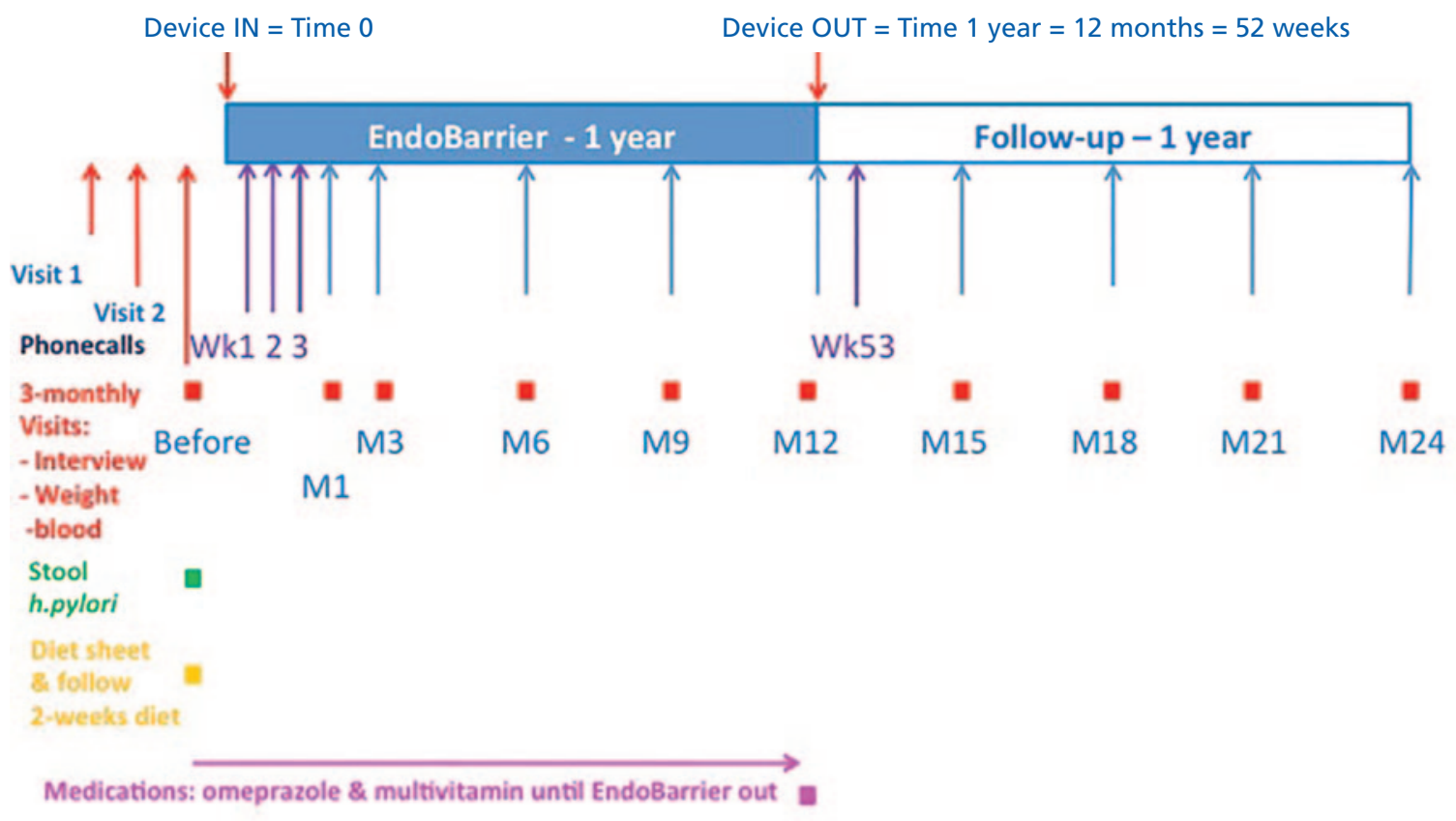

During the interval between the initial visits and EndoBarrier implantation, in some patients $\mathrm{HbA}_{1 \mathrm{c}}$ improved to $\leq 58$ $\mathrm{mmol} / \mathrm{mol}(7.5 \%)$. Such patients were given the previously offered EndoBarrier treatment. Patients taking aspirin or other antiplatelet medication that could not safely be stopped were excluded. Patients were required to agree to take high-dose proton pump inhibitors (omeprazole $40 \mathrm{mg}$ twice daily) throughout the period of EndoBarrier implantation. Helicobacter pylori was tested by stool antigen test and was checked before the patients began their omeprazole. Those who were screen positive were excluded unless this was eradicated using a $H$. pylori eradication protocol.

\section{Variables}

We recorded baseline age, sex, ethnicity, smoking history, diabetes duration and medications. At baseline and at 3-monthly intervals during the period following EndoBarrier insertion we measured $\mathrm{HbA}_{1 \mathrm{c}}$, weight and BMI, systolic blood pressure, cholesterol, HDL cholesterol, cardiovascular risk as assessed by the UKPDS Risk Engine v2, ${ }^{21}$ alanine aminotransferase (a marker of fatty liver disease), ${ }^{9}$ diabetes medications - including insulin total daily dose if applicable. We chose alanine aminotransferase as a marker of fatty liver disease because it is measured in routine clinical practice and because, in our REVISE-Diabesity research study, we used MRI scanning to measure reduction of liver fat in response to EndoBarrier and found that a fall in alanine aminotransferase reflected the reduction in fat demonstrated by the MRI scan. ${ }^{9}$ Side effects were recorded, in particular gastrointestinal side effects and any serious adverse events leading to early removal of the EndoBarrier. Patient satisfaction was assessed using the NHS Friends and Family Test. ${ }^{22}$ Weight and height were measured on standard outpatient equipment. Biochemistry parameters were measured in the pathology department at City Hospital.

\section{Sources of bias}

As we were auditing routine practice, we could not interfere with standard care which might have impacted on the results for example, medications for other conditions such as steroids for inflammatory conditions or medications for mental health. There was no control group for comparison and there was no blinding.

\section{Study size}

It was our intention to study all patients we treated with EndoBarrier in the same way. After EndoBarrier insertion in 62 such patients, the CE mark for EndoBarrier was suspended (November $2017)^{23}$ and we present here the data on all 62 patients up until the last device removal in November 2018.

\section{Statistical methods}

The impact of EndoBarrier on the parameters measured at follow-up was assessed by comparing the parameter in the last value measured prior to removal with the baseline value using a paired Student t-test. As all patients had to attend in order to have the EndoBarrier removed, removal data were obtained in all patients except one whose explantation occurred within 3 weeks of insertion.

\section{Results}

Between October 2014 when the service commenced and November 2017 when the last EndoBarrier was inserted, 62/174 
Table 1 Reasons why 112/174 (64\%) patients referred did not receive EndoBarrier treatment

\begin{tabular}{ll}
\hline Reason for not having EndoBarrier & $\mathbf{n}(\%)$ \\
\hline $\begin{array}{l}\text { Aspirin, clopidogrel or anticoagulants for cardio, } \\
\text { cerebral or peripheral vascular disease }\end{array}$ & $20(17.9)$ \\
Patient had not tried a GLP-1 receptor agonist & $17(15.2)$ \\
Patient declined & $17(15.2)$ \\
HbA $_{1 \text { c too low }}$ & $14(12.5)$ \\
Patient did not have diabetes & $10(8.9)$ \\
Considered unsuitable by gastroenterologists & $7(6.3)$ \\
Lost weight by diet & $7(6.3)$ \\
Did not attend & $6(5.4)$ \\
Lived too far away & $2(1.8)$ \\
Referred to End-OSA research study* & $2(1.8)$ \\
Too ill & $2(1.8)$ \\
Type 1 diabetes & $2(1.8)$ \\
Anaemia & $1(0.9)$ \\
Bariatric surgery preferred & $1(0.9)$ \\
Funding problems & $1(0.9)$ \\
Needs to be on non-steroidal anti-inflammatory agents & $1(0.9)$ \\
Previous bariatric intervention & $1(0.9)$ \\
Patient died before attending clinic & $1(0.9)$ \\
*EndoBarrier in diabetes with obstructive sleep apneoa & \\
ISRCTN33788132 https://doi.org/10.1186/ISRCTN33788132 & \\
&
\end{tabular}

(36\%) referrals to the service were accepted for EndoBarrier treatment after reference to eligibility criteria and full informed consent involving the patient concerned. Table 1 shows the reasons why 112 of the 174 patients (64\%) referred did not receive EndoBarrier treatment. Of the 62 patients accepted for EndoBarrier, one failed to comply with mandatory dietary advice to only eat puréed food during the second week after EndoBarrier insertion, which led to gastrointestinal haemorrhage so he had the EndoBarrier removed (patient 1, Table 5). Table 2 shows the baseline characteristics of the remaining 61 patients (age $51.4 \pm 7.2$ years, $54.1 \%$ male, 57.4\% Europid, diabetes duration 12.0 (8.0-19.5) years, $57.4 \%$ insulin-treated, BMl $41.9 \pm 7.4 \mathrm{~kg} / \mathrm{m}^{2}$ ).

Table 3 shows the main outcomes during the period of EndoBarrier implantation. During the period of EndoBarrier treatment mean \pm SD HbA 1 fell by $23.7 \pm 21.4 \mathrm{mmol} / \mathrm{mol}$ from $80.2 \pm 22.5$ to $56.5 \pm 11.5 \mathrm{mmol} / \mathrm{mol}(\mathrm{p}<0.001)$, weight fell by $15.9 \pm 8.5 \mathrm{~kg}$ from $122.6 \pm 27.9$ to $106.7 \pm 28.9 \mathrm{~kg}(p<0.001)$, systolic blood pressure from $138.5 \pm 15.0$ to $125.8 \pm 14.6 \mathrm{mmHg}(p<0.001)$, cholesterol from $4.7 \pm 1.4$ to $3.9 \pm 0.9 \mathrm{mmol} / \mathrm{L}(\mathrm{p}<0.001)$ and alanine aminotransferase from $33.2 \pm 19.8$ to $19.5 \pm 11.4 \mathrm{U} / \mathrm{L}$ $(\mathrm{p}<0.001)$. In the 35 insulin-treated patients, the median (IQR) insulin dose reduced from $100(54-140)$ to 40 (0-70) units $(p<0.001)$ with $10 / 35(28.6 \%)$ discontinuing insulin. As shown in Table 4, there were significant falls (UKPDS Risk Engine v2) in the risk of coronary heart disease (CHD) and stroke, suggesting that EndoBarrier treatment in 100 such patients could prevent eight events of CHD or stroke and save six lives over the 10 years.
Table 2 Baseline characteristics of 61 patients with implant and explant data

\begin{tabular}{ll}
\hline Parameter & $\mathbf{n}=\mathbf{6 1}$ \\
\hline Age (years) & $51.4 \pm 7.2$ \\
Sex (\% male) & 54.1 \\
Ethnicity: & \\
$\quad \%$ White & 57.4 \\
\% Afro-Caribbean & 16.4 \\
\% Asian-Indian & 26.2 \\
Smoking: & \\
\% Never smoked & 54.1 \\
\% Past smoker & 26.2 \\
Weight (kg) & 19.7 \\
\hline BMl (kg/m²) & $122.6 \pm 27.9$ \\
HbA 1 (mmol/mol) & $41.9 \pm 7.4$ \\
\hline HbA 1 (\%) & $80.2 \pm 22.5$ \\
Diabetes duration (Median[IQR] years) & $9.5 \pm 2.1$ \\
Taking insulin (\%) & $12.0(8.0-19.5)$ \\
\hline
\end{tabular}

Table 3 The impact of EndoBarrier treatment on mean \pm SD weight, $\mathrm{HbA}_{1 \mathrm{c}}$ and $\mathrm{CVD}$ risk factors and alanine aminotransferase (ALT - a liver fat marker) in 61 patients. There were highly significant falls in all parameters involved in CVD risk assessment other than HDL cholesterol which remained unchanged.

\begin{tabular}{|c|c|c|c|c|}
\hline Parameter & Baseline & At explant & Difference & p-value \\
\hline Weight (kg) & $122.6 \pm 27.9$ & $106.7 \pm 28.9$ & $-15.9 \pm 8.5$ & $<0.001$ \\
\hline BMI $\left(\mathrm{kg} / \mathrm{m}^{2}\right)$ & $41.9 \pm 7.4$ & $36.2 \pm 7.6$ & $-5.7 \pm 3.2$ & $<0.001$ \\
\hline $\mathrm{HbA}_{1 \mathrm{c}}(\mathrm{mmol} / \mathrm{mol})$ & $80.2 \pm 22.5$ & $56.5 \pm 11.5$ & $-23.7 \pm 21.4$ & $<0.001$ \\
\hline $\mathrm{HbA}_{1 \mathrm{c}}(\%)$ & $9.5 \pm 2.1$ & $7.3 \pm 1.1$ & $-2.2 \pm 2.0$ & $<0.001$ \\
\hline $\begin{array}{l}\text { Systolic blood } \\
\text { pressure }(\mathrm{mmHg})\end{array}$ & $138.5 \pm 15.0$ & $125.8 \pm 14.6$ & $-12.7 \pm 16.2$ & $<0.001$ \\
\hline Cholesterol (mmol/L) & $4.7 \pm 1.4$ & $3.9 \pm 0.9$ & $-0.86 \pm 1.13$ & $<0.001$ \\
\hline $\mathrm{HDL}(\mathrm{mmol} / \mathrm{L})$ & $1.13 \pm 0.27$ & $1.10 \pm 0.30$ & $0.04 \pm 0.22$ & 0.135 \\
\hline ALT (U/I) & $33.2 \pm 19.8$ & $19.5 \pm 11.4$ & $-13.7 \pm 20.1$ & $<0.001$ \\
\hline $\begin{array}{l}\text { Insulin daily dose } \\
\text { (median [IQR] } n=35)^{\star}\end{array}$ & $100(60-135)$ & $40(0-70)$ & -60 & $<0.001$ \\
\hline
\end{tabular}

\section{Early removal}

Ten of the 62 patients implanted with EndoBarrier (16\%) required early removal, four for gastrointestinal haemorrhage, two for liver abscess, one for another abdominal abscess and three for gastrointestinal symptoms. Table 5 gives the details of these 10 cases. In nine of these cases the EndoBarrier was retained for at least 2 months (median 273 days, range 61-336 days). In several cases there were issues with compliance which led to early removal, removals which may have been avoided with better compliance with dietary and/or medication advice (Table 5). All made a full recovery following device removal and most derived benefit despite the setback. Indeed, in the nine early removal patients who adhered to 
Table 4 EndoBarrier impact on 10-year CV risk as assessed by the UKPDS risk engine

\begin{tabular}{|c|c|c|c|c|c|c|}
\hline & $\begin{array}{l}\text { Before } \\
\text { EndoBarrier }\end{array}$ & $\begin{array}{l}\text { At EndoBarrier } \\
\text { removal }\end{array}$ & p-value & $\begin{array}{l}\text { Absolute } \\
\text { risk reduction }\end{array}$ & $\begin{array}{l}\text { Cases saved } \\
\text { (out of 100) }\end{array}$ & $\begin{array}{l}\text { Numbers } \\
\text { needed to treat }\end{array}$ \\
\hline $\mathrm{CHD}$ & $15.8 \pm 11.8$ & $9.0 \pm 6.0$ & $<0.001$ & $-6.8 \pm 7.6$ & 6.8 & 14.7 \\
\hline Stoke & $5.90 \pm 4.71$ & $4.84 \pm 3.70$ & $<0.001$ & $-1.06 \pm 1.50$ & 1.06 & 94.3 \\
\hline
\end{tabular}

Table 5 Serious adverse events (SAE) leading to early removal of EndoBarrier (EB)

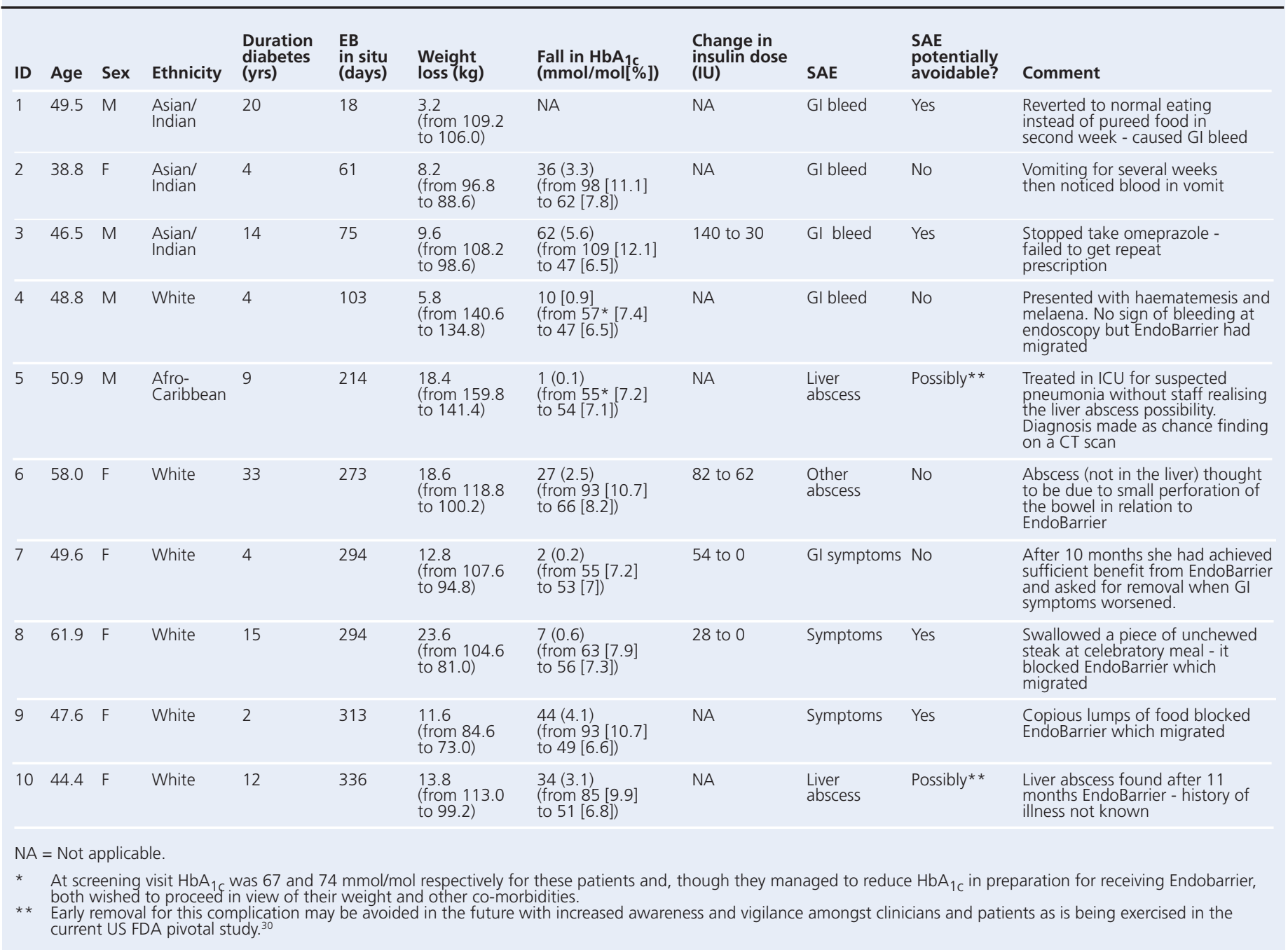

the dietary recommendations for the first 2 weeks (table 5, patients 2-10), mean $\pm \mathrm{SD} \mathrm{HbA}_{1 \mathrm{c}}$ fell by $24.8 \pm 21.2 \mathrm{mmol} / \mathrm{mol}$ from $78.7 \pm 21.2$ to $53.9 \pm 6.7 \mathrm{mmol} / \mathrm{mol}(\mathrm{p}=0.008)$ and weight fell by $13.6 \pm 5.7 \mathrm{~kg}$ from $114.9 \pm 22.8$ to $101.3 \pm 22.8 \mathrm{~kg}(\mathrm{p}<0.001)$. Thus, the improvements experienced by the early removal patients were not greatly different from those of the full cohort.

\section{Tolerability}

Aside from early removal due to gastrointestinal bleed or abscesses, 51/54 patients tolerated the device for its full planned year. In the remaining three cases who experienced gastrointestinal symptoms, the device was removed earlier than planned (Table 5). 
Figure 3. Patient satisfaction - NHS Friends and Family Test

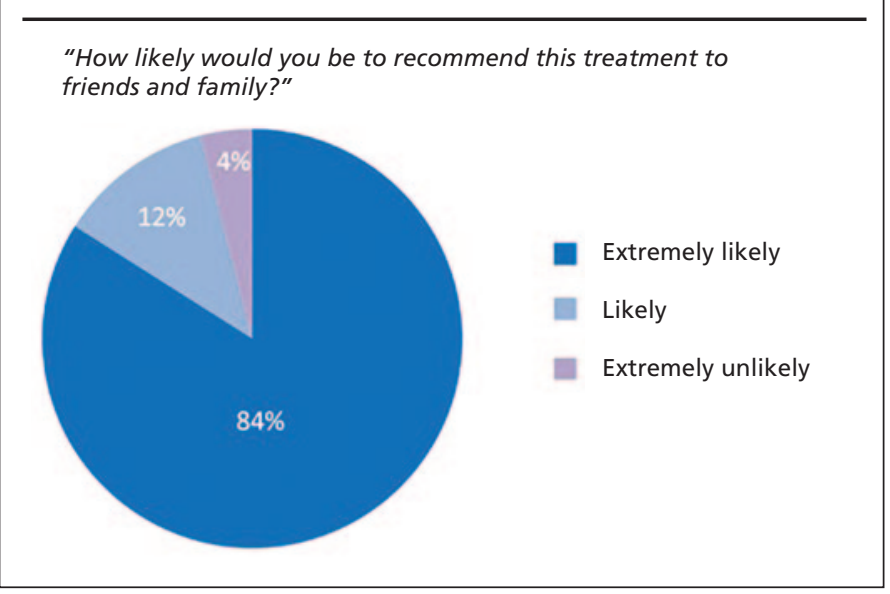

\section{Patient satisfaction}

It was our experience at clinic visits that patients typically reported a considerable increase in fitness and well-being, although we did not have any formal measure of this in our audit. Figure 3 shows the results from the NHS Friends and Family Test ${ }^{22}$ in response to the question: "How likely would you be to recommend this treatment to friends and family?". The benefits to the patients concerned are most readily appreciated from the pictorial examples and from interviews with them, both of which can be viewed online. ${ }^{24,25}$ These are typical of the group as a whole.

\section{Discussion}

\section{Key results}

In this first NHS service, EndoBarrier was used in patients with longstanding poorly controlled diabetes and obesity that was refractory to standard treatments. EndoBarrier resulted in considerable weight loss (mean $15.9 \mathrm{~kg}$ ), improvement in glycaemic control (mean 23.7 $\mathrm{mmol} / \mathrm{mol}$ from 82.2 to $56.5 \mathrm{mmol} / \mathrm{mol}$ ), significant reduction in a marker of fatty liver, improvement in cardiovascular risk and, for those on insulin, a considerable reduction in insulin dose with nearly $30 \%$ discontinuing insulin. As reducing $\mathrm{HbA} 1 \mathrm{c}$ and blood pressure is associated with improved microvascular outcomes, ${ }^{26-29}$ the risk of these was also improved. The device was generally well tolerated and $84 \%$ said they would be extremely likely to recommend the treatment to friends and family.

\section{Limitations}

The main limitation of this audit is the lack of a control group. All patients enrolled had a long history of attempts at weight loss and using hypoglycaemic medications known to help with weight loss, such as GLP-1 receptor agonists and SGLT2 inhibitors. Nevertheless, we cannot be sure from this cohort study what contribution there might have been from placebo effect or more intense follow-up. In the current pivotal study with EndoBarrier of the United States Food and Drug Administration $(F D A),{ }^{30}$ there is a sham control group who will receive an endoscopic examination without insertion of an EndoBarrier in a double-blind randomised fashion to address this issue. Further follow-up of the cohort after EndoBarrier explant is being undertaken to assess the extent to which the improvements are sustained. This is important as the benefits of improved cardiovascular and microvascular risk would be dependent on maintenance of improvement after removal of the device.

\section{Serious adverse events}

It is noteworthy that gastrointestinal bleeds occurred early after device insertion (18-103 days). A number of adverse events could potentially have been avoided (Table 5 ). In the light of our experience, it may be that many such events would in future be avoided in view of the increased education we would give to patients with regard to dietary compliance (avoidance of gastrointestinal haemorrhage [patient 1, Table 5] and gastrointestinal symptoms [patients 8 and 9, Table 5]) and adherence to mandatory medications (proton pump inhibitors [patient 3, Table 5]). In any future service there would be an awareness and focus on prevention of hepatic abscesses; however, as this was an emerging problem during the study, awareness and focus on prevention was not present at the beginning of this study. One of our patients was treated for suspected pneumonia in the Intensive Care Unit without those treating him having any idea that the problem might be hepatic abscess (patient 5, Table 5). Future information carried by patients and improved information given to patients would ensure much earlier detection of such problems. The reason for the occurrence of hepatic abscess as a complication is uncertain, but with the presence of a foreign body in the first part of the small intestine which becomes covered with bacteria, it is not unreasonable to presume that portal bacteraemia might occur, sometimes leading to infection in the liver. Strategies for reduction of this complication are being considered, including antibiotic prophylaxis, reduction of proton pump inhibitors and shortening of the treatment phase. In the current FDA pivotal trial, ${ }^{30}$ daily temperature monitoring is being proposed with monthly white blood cell and C-Reactive Protein assessment in an effort to identify - and hopefully treat - without removal of the EndoBarrier, any infection very early. There is a report of a patient with wellestablished hepatic abscess successfully treated with antibiotics without removal of the device; ${ }^{31}$ this patient was detected much later than it is hoped will occur in the FDA pivotal trial.

\section{Interpretation}

All the patients with early removal because of serious adverse events made a full recovery and most derived considerable benefit. Indeed, the mean $\mathrm{HbA}_{1 \mathrm{c}}$ fall of $24.8 \mathrm{mmol} / \mathrm{mol}$ and weight loss of $13.6 \mathrm{~kg}$ from $114.9 \pm 22.8$ to $101.3 \pm 22.8 \mathrm{~kg}(p<0.001)$ are improvements experienced by the early removal group that were not greatly different from those of the full cohort. EndoBarrier treatment requires only a relatively simple endoscopy procedure and it is noteworthy that endoscopy units and skilled endoscopists are ubiquitous throughout the NHS. In the context of the diabesity pandemic, there is a need for simpler treatments that are less invasive than bariatric surgery for the many patients with obesity and poorly controlled diabetes despite lifestyle and pharmaceutical interventions. Therefore, EndoBarrier deserves further investigation as potential treatment for wider use in refractory 


\section{Key messages}

- In people with obesity, poor glycaemic control and long duration of diabetes, EndoBarrier led to considerable improvement in weight, and microvascular risk as indicated by improvement in blood pressure and glycaemic control. There was a significant reduction in cardiovascular risk as assessed by the UKPDS risk engine.

- There was a reduction in a marker of fatty liver and in those on insulin, a considerable reduction in required insulin dose with 30\% discontinuing insulin

- All patients requiring early removal for serious adverse events or side effects (16\%) recovered fully and despite early removal derived benefit. In many, such problems could be avoided in the future by improved education and vigilance

- Patient satisfaction levels were high and these results from the first NHS EndoBarrier service are encouraging for EndoBarrier as a treatment for patients with long duration diabetes and obesity who remain with poor glycaemic control despite other diabetes treatments

diabesity, especially bearing in mind cardiovascular and microvascular risk to the patients if they are not given additional treatment.

\section{Generalisability}

Future use of EndoBarrier within the NHS is dependent on restoration of its CE mark, which was not renewed in November 2017 by the notified body at the time for reasons that are not entirely clear. ${ }^{23}$ The makers of EndoBarrier are now working with a new notified body with a view to imminent restoration of the CE mark. ${ }^{32}$ Endoscopy units are ubiquitous throughout the NHS, as are skilled endoscopists. Patients with refractory uncontrolled diabesity are also abundant throughout the NHS and therefore, should the CE mark be restored, it would be relatively easy to make EndoBarrier widely available. The lessons we have learned with regard to measures to minimise serious adverse events would also be useful to future services.

Conflict of interest REJR: speaker fees and/or consultancy fees and/or educational sponsorships from AstraZeneca, BioQuest, GI Dynamics, Janssen, Novo Nordisk, Sanofi-Aventis and Takeda. Other authors none

\section{Funding None}

Acknowledgement The success of the project was down to a team effort with many people involved. We would like thank in particular all of the endoscopy, anaesthetic and diabetes staff involved in the care of these patients, and Dominic Jackson from Elemental Healthcare Limited who supported with his long standing expertise with EndoBarrier. Special thanks to Melanie Wyres who was the administrative rock at the core of the project. And finally thanks to our chief executive, Toby Lewis, for his crucial support in getting this innovative new service established in our busy hospital despite so many other priorities, and for facilitating negotiations with the local CCG.

\section{References}

1. The EndoBarrier Gastrointestinal Liner with Delivery System: instructions for use. GID part number 50-10-00552 Rev N. http://gidynamics.com/wp-content/uploads/2017/09/50-10-00552-Rev-N-IFU-EB-GI-Liner-with-DeliverySystem.pdf (accessed 10 September 2019)

2. de Jonge C, Rensen SS, Verdam FJ, et al. Endoscopic duodenal-jejunal bypass liner rapidly improves type 2 diabetes. Obes Surg 2013;23:135460. https://doi.org/10.1007/s11695-013-0921-3

3. Betzel B, Homan J, Aarts EO, et al. Weight reduction and improvement in diabetes by the duodenal-jejunal bypass liner: a 198 patient cohort study. Surg Endosc 2017;31:2881-91. https://doi.org/10.1007/s00464-016-52996

4. Kaválková P, Mráz M, Trachta P, et al. Endocrine effects of duodenal-jejunal exclusion in obese patients with type 2 diabetes mellitus. J Endocrinol 2016; 231:11-22. https://doi.org/10.1530/JOE-16-0206

5. Koehestanie P, Dogan K, Berends F, et al. Duodenal-jejunal bypass liner implantation provokes rapid weight loss and improved glycemic control, accompanied by elevated fasting ghrelin levels. Endosc Int Open 2014; 2(1):E21-E27. https://doi.org/10.1055/s-0034-1365222

6. Jirapinyo, Haas AV, Thompson CC. Effect of the duodenal-jejunal bypass liner on glycemic control in patients with type 2 diabetes with obesity: a meta-analysis with secondary analysis on weight loss and hormonal changes. Diabetes Care 2018;41(5):1106-15. https://doi.org/10.2337/dc17-1985

7. Sen Gupta P, Drummond RS, McGowan BM, et al. One year efficacy, safety and tolerability of duodenal exclusion using Endobarrier as an adjunct to glucagonlike-peptide-1 (GLP-1) therapy: a randomised controlled trial. Diabetologia 2016;59(Suppl 1):S272, 569.

8. Ryder REJ. One year efficacy, safety and tolerability of duodenal exclusion using Endobarrier as an adjunct to glucagon-like-peptide-1 (GLP-1) therapy: a randomised controlled trial. ePoster video presentation, European Association for the Study of Diabetes, Munich, 2016. https://www.easd.org/virtualmeeting/home.html\#! resources/one-year-efficacy-safety-and-tolerabilityof-duodenal-exclusion-using-endobarrier-as-an-adjunct-to-glucagon-likepeptide-1-glp-1-therapy-a-randomised-controlled-trial-fe99ad0e-09184199-9aa7-a423f5555b65 (accessed 10 September 2019)

9. Hayee B, Sen Gupta P, Anderson M, et al. Endoscopic proximal intestinal exclusion can improve non-alcoholic fatty liver disease (NAFLD) in patients with diabesity. Proceedings of the Digestive Diseases Week (DDW), San Diego, May 2016.

10. International Diabetes Federation. IDF Diabetes Atlas, 8th edn. Brussels, Belgium: International Diabetes Federation, 2017.

11. Lim EL, Hollingsworth KG, Aribisala BS, et al. Reversal of type 2 diabetes: normalisation of beta cell function in association with decreased pancreas and liver triacylglycerol. Diabetologia 2011;54(10):2506-14. https://doi.org/ 10.1007/s00125-011-2204-7

12. Davies MJ. Management of hyperglycaemia in type 2 diabetes: the 2018 consensus report by ADA/EASD Insights from one of the authors. $\mathrm{Br} J$ Diabetes 2018;18:137-40. https://doi.org/10.15277/bjd.2018.193

13. Davies MJ, D'Alessio DA, Fradkin J, et al. Management of hyperglycaemia in type 2 diabetes, 2018. A consensus report by the American Diabetes Association (ADA) and the European Association for the Study of Diabetes (EASD). Diabetologia 2018;61(12):2461-98. https://doi.org/10.1007/ s00125-018-4729-5

14. Riddle MC, Rosenstock J, Gerich J, et al. The treat-to-target trial: randomized addition of glargine or human NPH insulin to oral therapy of type 2 diabetic patients. Diabetes Care 2003;26(11):3080-6. https://doi.org/10.2337/diacare.26.11.3080

15. National Institute for Health and Care Excellence (NICE). Insulin therapy in type 2 diabetes. Last revised July 2016. https://cks.nice.org.uk/insulin-therapy-in-type-2-diabetes\#!scenario (accessed 9 September 2019).

16. Heine RJ, Van Gaal LF, Johns D, et al. Exenatide versus insulin glargine in patients with suboptimally controlled type 2 diabetes: a randomized trial. Ann Intern Med 2005;143(8):559-69. https://doi.org/10.7326/0003-4819143-8-200510180-00006

17. Pories WJ, Caro JF, Flickinger EG, et al. The control of diabetes mellitus (NIDDM) in the morbidly obese with the Greenville Gastric Bypass. Ann Surg 1987;206:316-23. https://doi.org/10.1097/00000658-198709000-00009

18. Rubino F, Forgione A, Cummings DE, et al. The mechanism of diabetes control after gastrointestinal bypass surgery reveals a role of the proximal small 
intestine in the pathophysiology of type 2 diabetes. Ann Surg 2006; 244:741-9. https://doi.org/10.1097/01.sla.0000224726.61448.1b

19. Kashyap SR, Daud S, Kelly KR, et al. Acute effects of gastric bypass vs gastric restrictive surgery on beta-cell function and insulinotropic hormones in severely obese patients with type 2 diabetes. Int J Obes (Lond) 2010; 34:462-71. https://doi.org/10.1038/ijo.2009.254

20. The ABCD EndoBarrier Worldwide Registry. https://abcd.care/worldwideendobarrier-registry (accessed 8 November 2019).

21. The UKPDS Risk Engine v2.0. https://www.dtu.ox.ac.uk/riskengine/ (accessed 10 September 2019)

22. NHS England. Friends and Family Test. https://www.england.nhs.uk/fft/ (accessed 10 September 2019).

23. GI Dynamics. GI Dynamics receives CE Certificate of Conformity withdrawal notice for EndoBarrier. https://gidynamics.com/2017/11/12/gi-dynamics-receives-ce-certificate-conformity-withdrawal-notice-endobarrier/ (accessed 11 September 2019)

24. Birmingham EndoBarrier Treated Patients. Pictures obtained with written consent for online publication. http://www. diabetologists-abcd.org.uk/Endobarrier/Birmingham_Endobarrier_patients.pdf (accessed 1 November 2019).

25. Interviews with Birmingham EndoBarrier Treated patients. Video footage obtained with written consent for online publication. https://tinyurl.com/ y4pwwokc (accessed 1 November 2019).

26. United Kingdom Prospective Diabetes Study (UKPDS). Main Trial. https://www.dtu.ox.ac.uk/ukpds/ (accessed 10 September 2019).

27. UK Prospective Diabetes Study Group. Tight blood pressure control and risk of macrovascular and microvascular complications in type 2 diabetes: UKPDS 38. BMJ 1998;317:703-13. https://doi.org/10.1136/ bmj.317.7160.703

28. UK Prospective Diabetes Study Group. Efficacy of atenolol and captopril in reducing risk of macrovascular and microvascular complications in type 2 diabetes: UKPDS 39. BMJ 1998;317:713-20. https://doi.org/10.1136/ bmj.317.7160.713

29. UK Prospective Diabetes Study (UKPDS) Group. Intensive blood-glucose control with sulphonylureas or insulin compared with conventional treatment and risk of complications in patients with type 2 diabetes (UKPDS 33). Lancet 1998;352(9131):837-53. https://doi.org/10.1016/S01406736(98)07019-6

30. GI Dynamics. A randomized, multi-center, pivotal efficacy and safety study evaluating the EndoBarrier ${ }^{\circledR}$ system for glycemic improvement in patients with inadequately controlled type 2 diabetes and obesity (FDA IDE STEP-1 study). https://gidynamics.com/2018/08/12/gi-dynamics-announces-fda-approval-endobarrier-pivotal-trial/ (accessed 10 September 2019).

31. Drummond RS, Timmons J, Talla M, Sen Gupta P, Ryder REJ. Liver abscess secondary to a duodenal-jejunal bypass liner (DJBL) successfully treated with antibiotics but without removal of the device. Proceedings of the $A B C D$ Spring Meeting, 2018. https://abcd.care/resource/liver-abscess-secondaryduodenal-jejunal-bypass-liner-djbl-successfully-treated-0 (accessed 27 November 2019).

32. GI Dynamics Announces Selection of New Notified Body. https://gidynamics.com/2018/10/05/gi-dynamics-announces-selection-new-notified-body/ (accessed 5 November 2019).
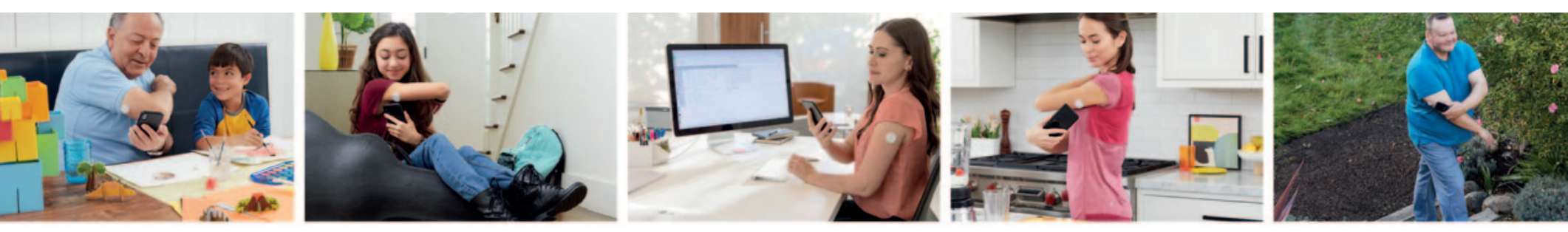

\section{Digital health tools that work together for seamless diabetes management}

\section{Freestyle Libre

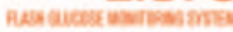

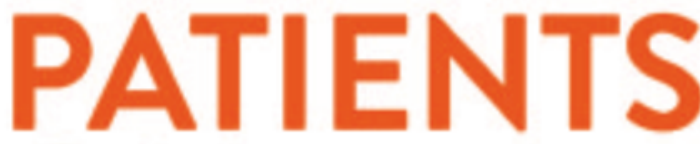
Car CAN DO IT WITHOUT LANCETS ${ }^{1}$

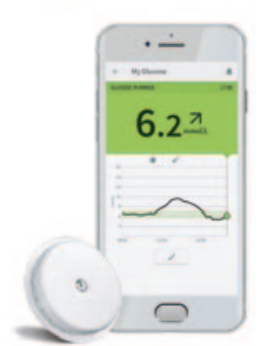

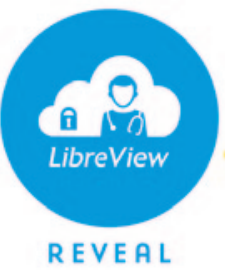

Healthcare providers have secure, online access to glucose insights ${ }^{2,3}$

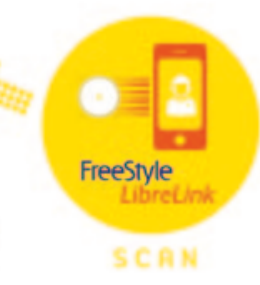

Patients can conveniently check their glucose using their phone $e^{4.5}$

\section{For more information, please visit} www.FreeStyleDiabetes.co.uk

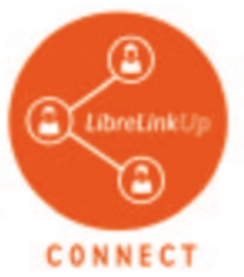

Caregivers can remotely monitor their loved ones ${ }^{6}$

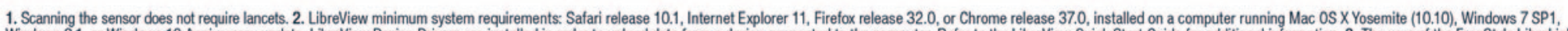

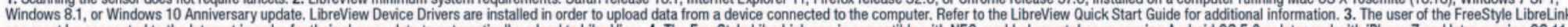

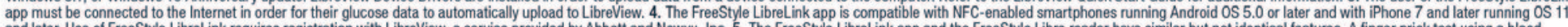

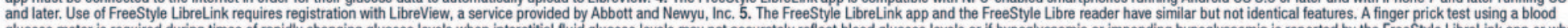

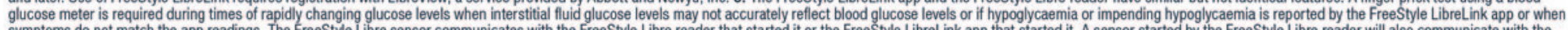

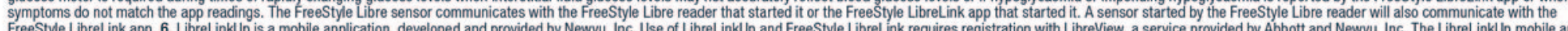

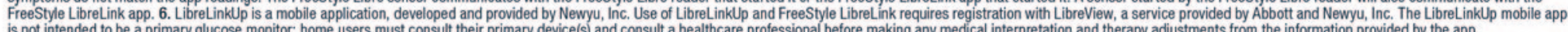

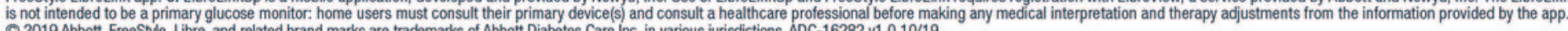
O 2019 Abbott. FreeStyle, Libre, and related brand marks are trademarks of Abbott Diabetes Care Inc. in various jurisdictions. ADC-16282 v1.0 10/19
} 